\title{
低氣壓について $(1)^{*}$ \\ 三 浦 武 亞
}

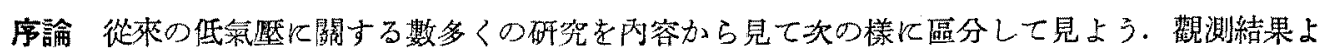
り歸納される經驗法則及び之を恱明せんとする又は指導する理諭法則である。 ての小文飞於ては觀

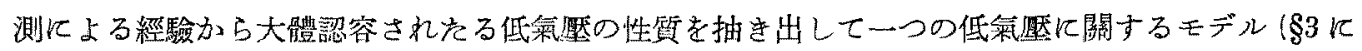

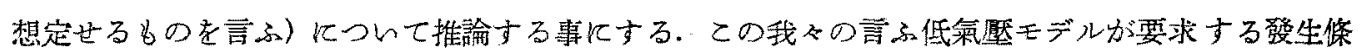

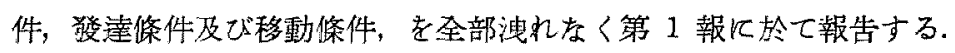

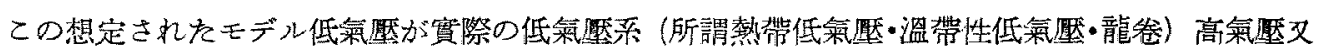

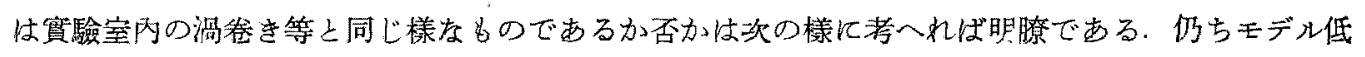

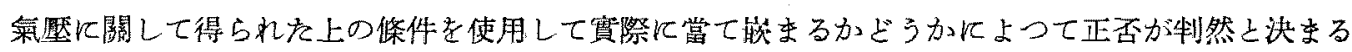
わけである。

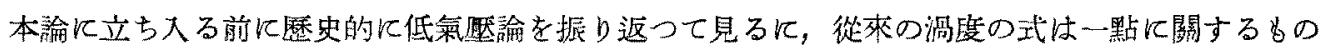

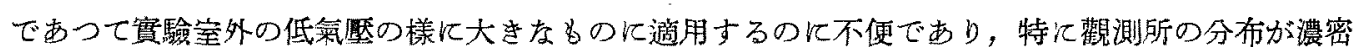
になってるないため視的飞渦度を論亦ると言ふ炕適當でない，理論的には波動諭等があるがい

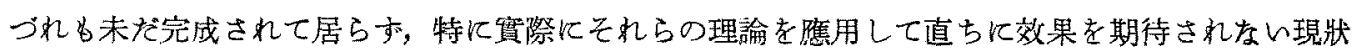
である。

ビャークネスの循環加速の定理は傾原大氣を問題にした點で優れをるのであるが粘性を無視し及 立體的な低氮塺を問題にして我ふの要求する條件を滿足するには至つてるない，

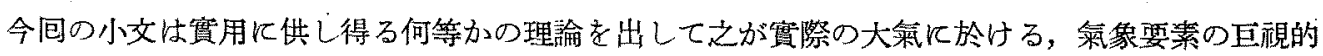

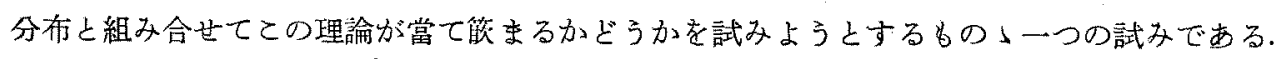

\section{§1. 記 號}

$\mathfrak{B}$ 風速度: u.v.w $x-, y-, z-$ 方向の成分之す

$\mathfrak{A}$ 渦度 $\operatorname{rot} \mathfrak{B}=2 \mathfrak{A}$

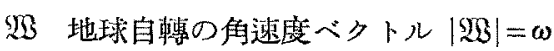

$\mathfrak{R}$ 單位質量飞働く外力

$\rho$ 空氮の密度 $R$ 普遍ガス常数 $m$ ーグラム分子.

$p$ 大氣厢

$\varphi$ 坐標の原點以關する緯度ニ北を正とする

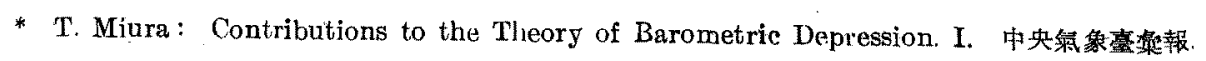


$\nu=\frac{\mu}{\rho}$ 動的粘性係數

$\tau$ 考へてるる空間（單連空閒を一般化探用する）

$\sigma$ はその表面

$t$ 時閒坐標

$n \quad \sigma$ K對する内法線 $(x y)$ 面に投射したものを $\eta$ とする

$\xi$ 水平な面上 $\tau$ との交線 $\tau$ を左にして前方を正にるる

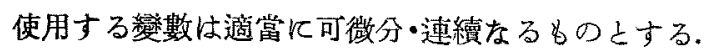

脚符 $h$ は水本に閣し

脚符 $x, y, z, h, n$ 等はベクトルの夫ょの脚符の方向に於ける成分を示す.

\section{§2、坐標及び運動方程式}

坐標は地面に靜止せる觀測者について取る事にする $x, y, z$ 考直角右手系坐標にして

$$
x \text { 一南, } y \text {-東, } z \text { 一上 }
$$

炕取る事にする。

大氣恃壓縮及び粘性のあるものと考へて，ナビヤー・ストークスの運動方程式を探用する事にす る.

$$
\frac{\partial \mathfrak{B}}{\partial t}=-(\mathfrak{B} \cdot \nabla) \mathfrak{B}-2[\mathfrak{B} \times \mathfrak{B}]+\mathfrak{R}-\frac{1}{\rho} \operatorname{grad} p+\frac{\nu}{3} \operatorname{grad} \operatorname{div} \mathfrak{B}+\nu \nabla \mathfrak{B}
$$

連續の式

$$
\frac{\partial \rho}{\partial t}+\operatorname{div}(p \mathfrak{B})=0
$$

室氣體の狀態方程式

$$
\rho \frac{R}{m} T=p
$$

\section{§3、渦度と低氣壓}

低氣壓のモデルとして渦卷をによつて運動する空氣系を考へる事にする，乃ち次の樣なものを想 定する.

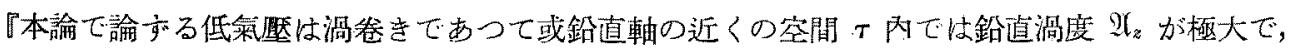

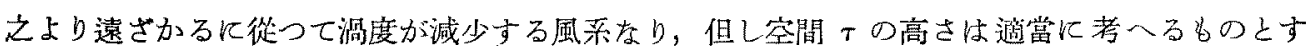
马』

この如き低氣厴は一般の經驗と矛盾するものでるい，本文では今後單に低氣鷢と言へば特に斷ら 伖りからる意味で使用して置くものとする，又之は古くは藤原博士の研究その他により大體認め

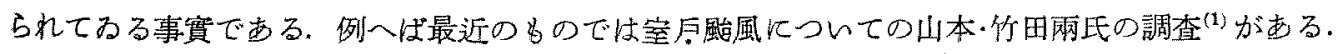
想定 (2) K從つて次の積分をつくつて見る

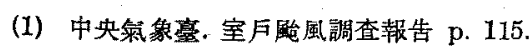




$$
\iiint_{\tau} \mathfrak{\mathfrak { U } _ { z }} d \tau
$$

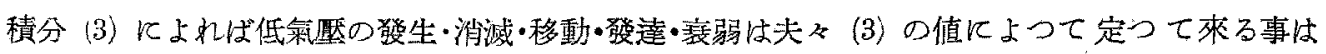
明瞭である。

\section{§4. 渦度補給の式の摭張}

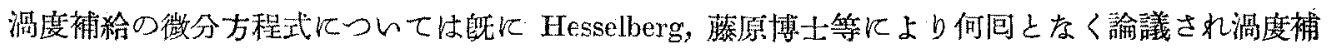

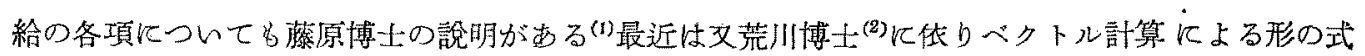

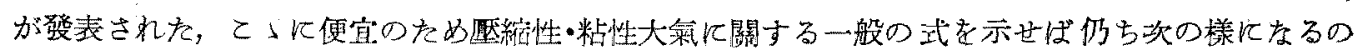
は周知の通りである。

$$
\begin{aligned}
& \frac{\partial \mathfrak{I}}{\partial t}+(\mathfrak{B} \cdot \nabla) \mathfrak{Q}+\operatorname{div} \mathfrak{B} \cdot \mathfrak{X}-(\mathfrak{A} \cdot \nabla) \mathfrak{B} \\
& +(\mathfrak{B} \cdot \nabla) \mathfrak{B}+\operatorname{div} \mathfrak{B} \cdot \mathfrak{B}-(\mathfrak{B} \cdot \nabla) \mathfrak{B} \\
& =\frac{1}{2} \operatorname{rot} \mathfrak{A}-\frac{1}{2} \operatorname{rot} \frac{\operatorname{grad} p}{\rho}+\nu \nabla^{2} \mathfrak{A}
\end{aligned}
$$

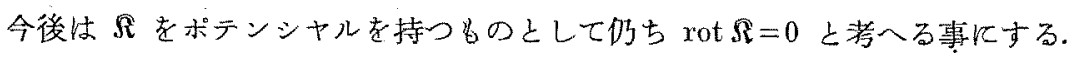

こなで (4)(5)より（4)の空間積分をとつて見よう，更に $Z$ 成分を゙けを取る事にして $\iiint \frac{\partial \mathfrak{U}_{z}}{\partial t} d \tau$ $=\frac{\partial}{\partial t} \iiint \mathfrak{U}_{z} d \tau$ なる事に注目する ${ }^{(3)}$. この樍分について第 1 項以外恃面樍分に變換される. 简單 な勘定により體積分に關与る多の消えてしまつて結局の所として次の式を得る

$$
\frac{\partial}{\partial t} \iiint \mathfrak{A}_{z} d \tau=A+W+V+B
$$

rsk

$$
\begin{aligned}
A & =\iint\left(\mathfrak{B}_{n} \mathfrak{U}_{z}-w \mathfrak{U}_{n}\right) d \sigma \\
& =\iint \mathfrak{A}_{z} \mathfrak{B}_{h} \sin (n \cdot z) \cos \left(\eta, \mathfrak{W}_{h}\right) d \sigma-\iint \mathfrak{I}_{h} w \sin (n \cdot z) \cos \left(\eta \cdot \mathfrak{A}_{h}\right) d \sigma \\
W & =\iint\left(\mathfrak{B}_{n} \mathfrak{M}_{z}-w \mathfrak{B}_{n}\right) d \sigma \\
& =\mathfrak{W}_{z} \iint \mathfrak{B}_{h} \cos \left(n \cdot \mathfrak{B}_{h}\right) d \sigma-\mathfrak{M}_{x} \iint w \cos (n \cdot x) d \sigma
\end{aligned}
$$

（1）藤原博士，大氣物理學 p. 131 但し湖註 4 參照.

(2) 昭和 16 年 5 月氣象集誌.

脚部 4

$$
\text { (3) ては } t \text { の函數でないと洘へてるるから }
$$

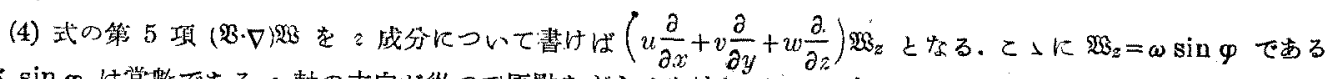

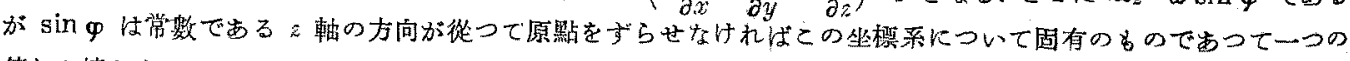

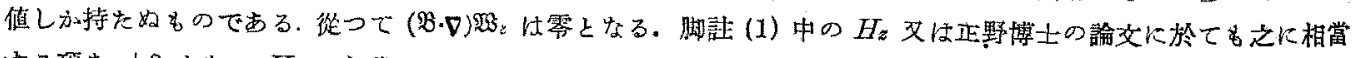

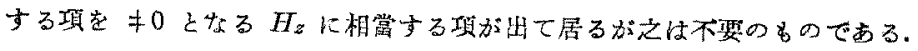




$$
\begin{aligned}
& V=-v \iint \frac{\partial \mathfrak{A}_{z}}{\partial n} d \sigma \\
& B=-\frac{1}{2} \iint \frac{1}{\rho} \frac{\partial p}{\partial \xi} \sin (n, z) d \sigma
\end{aligned}
$$

狀態力程式 ( $\left.1^{\prime \prime}\right)$ を使つて (10)を書を鮕へれば

$$
=-\frac{1}{2} \frac{R}{m} \iint T \frac{\partial \log p}{\partial \xi} \sin (n \cdot z) d \sigma
$$

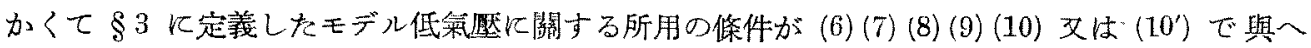

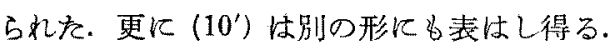

以上では $(6)-\left(10^{\prime}\right)$ を導く途中の計算を全部省略して終つた。 ての途中の計算は差程面倒でなく 普通の敎科書にある部分積分の定理だけである.

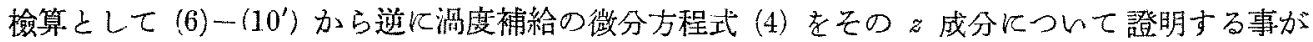
出來る. 郎ち (6) は (4) と同等な內容を持つてるる事が分る.

\section{§5、モデル低氣壓に關する條件 $A, B, W, V$ の吟味}

以上の議論では匊象要素壮空閒內で迎續で然も必要なだけ徽分可能とした，之等については實際 の大氣に應用する前に一應の吟味を必要とする. 內部に所謂不連續面を含む場合にはどうなるか。 之に對する解答としては所謂不連面に於ける變化を有する有限ではあるが狹い距離に於ける連續

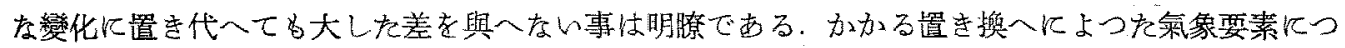

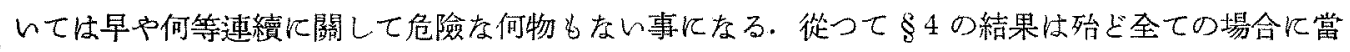
歕ると考へられる。

もら一つの問題壮境界面が內部空間に存在する場合である，例人ば鷹埃・水滴・又は普通の物體が 有る時大勢飞影響を及情す樣な事がないが゙うかである。

ての場合物體內に空氣の流入がない索のとすれば

$$
\mathfrak{B}_{n}=0
$$

故に之等の面の一つが寄與する渦度は次の 4 つとなる

$$
\begin{aligned}
& A_{1}=-\iint w \mathfrak{A}_{n} d \sigma \\
& W_{1}=-\iint w \mathfrak{B}_{n} d \sigma=-w \iint \omega \cos (n \cdot \mathfrak{B}) d \sigma \\
& V_{1}=-\nu \iint \frac{\partial \mathfrak{U}_{z}}{n} d \sigma \\
& B_{1}=-\frac{1}{2} \frac{R}{m} \iint T \frac{\partial \log p}{\partial \xi} \sin (n \cdot z) d \sigma
\end{aligned}
$$

然し本文に於ては一先つ之等は省略する事にする. 
從つて前 $\xi の$ 條件が滿足されるのは空間內に固形物又は水滴の如きものを含まない空間であ る。

然し乍ら一般には之等の假定は上式よりみて物體が小さくて風に自由に流される様な慣性の小な る場合には大體無視されるものと見做す事にする。

要するに上の議論は完全な不連續面の存在を無視した場合について成り立つ事を言つたものであ つて今後ての假定を以て推諭する必要热れば不漸續を假定する事にする.

\section{§6. $A, W, \boldsymbol{W}, \boldsymbol{B}$ の夫んの大きさの吟昧}

之等補給の各貞の大いさを見るため積分函數の大いさの見當をつけて見る事にする

$$
\begin{aligned}
& A \cdots \cdots\left\{\mathfrak{A}_{z} \mathfrak{B}_{h} \cos \left(\eta, \mathfrak{N}_{h}\right)-\mathfrak{U}_{h} w \cos (\eta, \mathfrak{U})\right\} \sin (n . z) \\
& B \cdots \cdots-\frac{1}{2} \frac{1}{\rho} \frac{\partial p}{\partial \xi} \sin (n, z) \\
& W \cdots \cdots \mathfrak{B}_{z} \mathfrak{B}_{h} \cos \left(n . \mathfrak{B}_{h}\right)-\mathfrak{S B}_{x} w \cos (n . x) \\
& \nabla \cdots \cdots-\nu \frac{\partial \mathfrak{A}_{z}}{\partial n}
\end{aligned}
$$

各要索の大いさを次の大んさで見樍る(e.g.s)

$$
\begin{gathered}
\mathfrak{U}_{z}=10^{-5} \sim 10^{-4} \quad w=10^{-4} \sim 10^{\circ} \quad \mathfrak{B}_{H}=10^{2} \sim 10^{3} \quad \nu=10^{4} \sim 10^{5} \quad \mathfrak{U}_{H}=10^{-3} \sim 10^{-2} \quad p=10^{6} \\
\frac{\partial \mathfrak{S}_{z}}{\partial z}=10^{-12} \sim 10^{-11} \quad \frac{\partial \mathfrak{A}_{z}}{\partial \xi}=10^{-10} \sim 10^{-9} \quad \frac{\partial p}{\partial \xi}=10^{-5} \sim 10^{-4} \quad \frac{1}{\rho}=10^{3}
\end{gathered}
$$

之等は Hesselberg と Friedmann(1)の與へたものであるが之を使へば $A B W V$ は夫ふ次の様にな， る

$$
\begin{aligned}
& A \cdots \cdots\left(10^{-3} \sim 10^{-1}\right)+\left(10^{-5} \sim 10^{-2}\right) \\
& B \cdots \cdots \div 0^{-2} \sim 10^{-1} \\
& W \cdots \cdots\left(10^{-2} \sim 10^{-1}+\left(10^{-6} \sim 10^{-4}\right)\right. \\
& V \cdots \cdots 10^{-6} \sim 10^{-4} \text { (側面) } \quad 10^{-8} \sim 10^{-6} \text { (上面) }
\end{aligned}
$$

然し乍ら $\mathfrak{B}_{z}=\omega \sin \varphi, \mathfrak{B}_{x}=-w \cos \varphi$ であるから赤道に於ては $\varphi=0^{\circ} \quad \therefore \mathfrak{M}_{z}=0 \mathfrak{M}_{x}=-\omega$ 之なり地理的飞分布せるものであるから，上式を使用するに注意を要するの性論でする。

1 例上して颱風についてての大レ゙さがどの程度のものになるか計算して見よう．低繰度に發生す

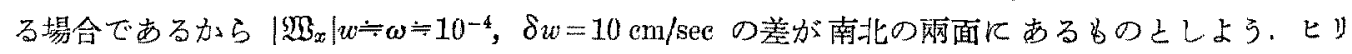
ッピンの東の岡田博士の低氣壓谷について $W$ に主に利てて來るのは $\left|\mathfrak{S B}_{x}\right|$ によるもの之考入南北 の長さを $1000 \mathrm{~km}$ として見る，渦度が $10^{-5}$ だけとの區域內に一樣に增加するには $N$ 日を要する

(1) Hesselberg und Friedmann, Die Größenordung der meteorologischen Elemente und ihrer räumlichen und zeitlichen Ableitungen. Veröff Geophys. Inst. Univ. Leip. 1, 147-173 (1941) 交獻抄, 第 1 叁仯抄錄あり。 
とすれば仍ちそのオーダーは

$$
N \doteqdot \frac{1000 \mathrm{~cm} \times 10^{-5} / \mathrm{sec}}{10 \mathrm{~cm} / \mathrm{sec} .10^{-4} / \mathrm{sec}} \fallingdotseq 10^{6} \mathrm{sec} \fallingdotseq \frac{10^{6}}{10^{5}} \text { 日 }=10 \text { 日 }
$$

の程度であるから數日乃至數十日間むれば大體風風の卵程度の渜は $\mathfrak{B}_{x}$ とwとより補給される事 が分り實際の物についても一概に $W$ の第 2 項を無視する譯には行かをい事が分る.

上は唯W の第2 項を簡單に吟味しをだけですつて實祭問題としては他の項を考虑しなければ ならない事は云方迄もない。

\section{$\S$ 結 言}

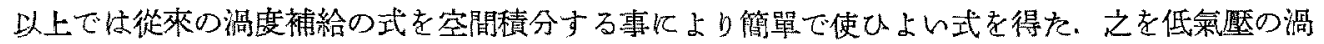
度と關係づけてその發達の段階が新しく導いた焵度の式で表はされる場合の式が得られた。とのモ

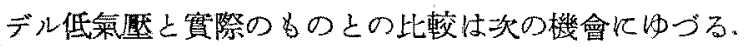

終にいつも乍ら御鞭撻下さいます岡田先生及び閲讀と批䚵して㛊解を注意して戴きをした藤原先 生に文普段敎示を受けてるる本多先生にも厚く御禮中し上げます。

附記 藤原先生は本論文几就て。

(1) 欽遖渦度の積分空間は數學的に任意であるが，實際問題として具體的に高氣壓或は低氣壓の 發達を論和るに當つては，空間を適當に採らね舛ならぬ。

（2）乙の空間內に不連續面を含む時䏠，不連續面の存在に上る渦度の生成があるからとの點をる 考虑を要する.

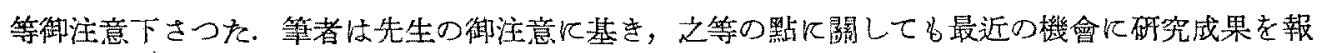
告したい思つて居る.

\section{要 報}

曲線座標飞よるエネルギー減袬定理*

\section{（水平安定の限界 第四報）}

荒川秀俊

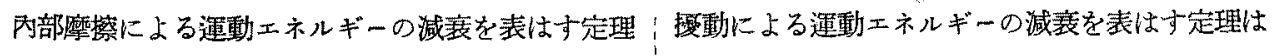 は

$$
\frac{d E}{d t}=-\iiint \Phi d x d y d \hat{\alpha}
$$

$$
\frac{d E}{d t}=-\iiint \Phi d x d y d z-\iiint y \cdot d x d y d z \text {. }
$$
但し考ふる流體が外力を受くることなく叉凬體の境界

\footnotetext{
* H, Arakawa: Dissipationstheorem der Turbulenter Flüssigkeitsbewegungen.
} 